\section{Clinical vignette}

\section{Left ventricular wall invaded by thyroid cancer metastasis}

\author{
Jakub Zieliński, Piotr Kołsut, Mariusz Kuśmierczyk, Jarosław Kuriata
}

Department of Cardiac Surgery and Transplantology, National Institute of Cardiology, Warsaw, Poland

Correspondence to:

Jakub Zieliński, MD,

Department of Cardiac

Surgery and Transplantology,

National Institute of Cardiology,

ul. Alpejska 42, 04-628 Warszawa,

Poland, phone: +48223434211 ,

email: zielinski5@vp.pl

Received: October 9, 2020.

Revision accepted:

December 8, 2020.

Published online:

December 21, 2020.

Kardiol Pol. 2021; 79 (1): 89-90

doi:10.33963/KP.15721

Copyright by the Author(s), 2021
Thyroid cancer constitutes $1 \%$ to $5 \%$ of all malignancies worldwide and its incidence is expected to increase. Follicular thyroid cancer is the second most common type of thyroid cancer, representing approximately $10 \%$ of all malignant thyroid tumors in iodine-sufficient areas. ${ }^{1}$ Metastasis of epithelial thyroid cancer cells to the myocardium is an extremely rare but potentially severe complication. ${ }^{2}$

We describe a case of a 57-year-old woman with poorly differentiated metastatic follicular thyroid cancer, who was admitted to our department in June 2020 for surgical removal of a mass infiltrating the left ventricular wall. She was diagnosed with cancer (morphological code 8020/3 according to the World Health Organization histological classification; with a follicular appearance) 12 years earlier. Treatment included
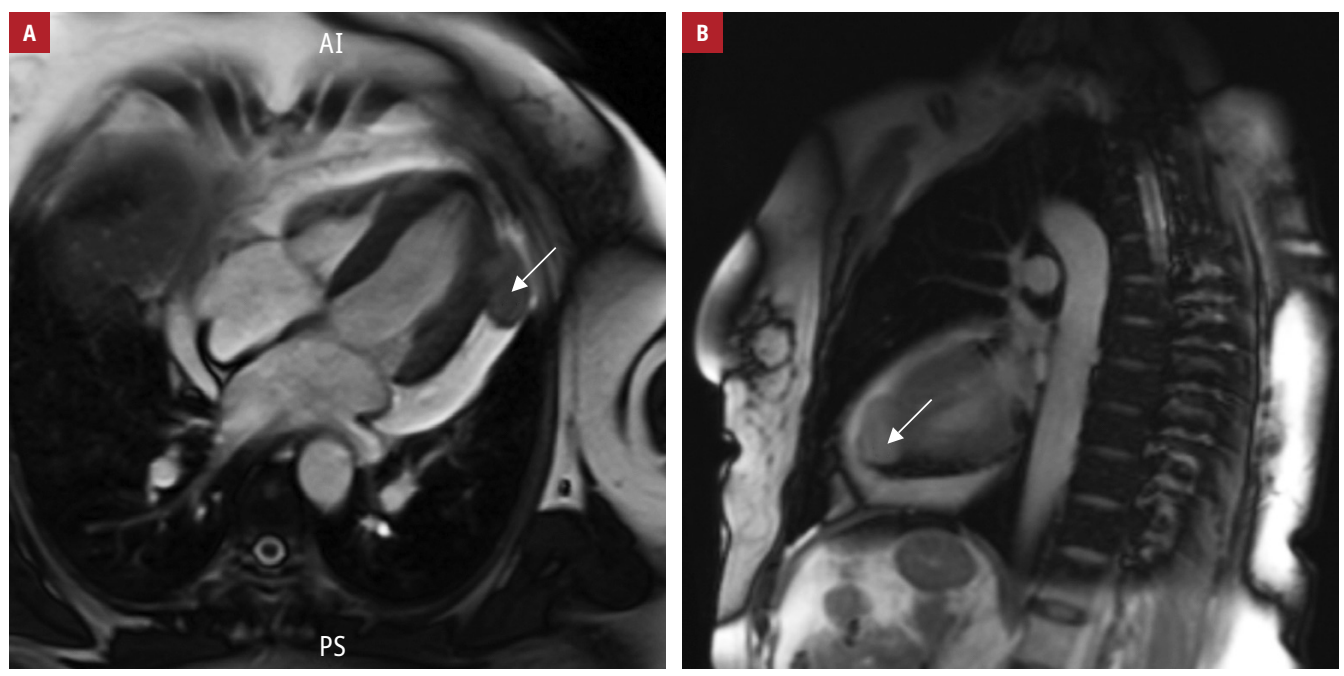

FIGURE 1 A - magnetic resonance imaging, transverse view (tumor indicated by the arrow); B - magnetic resonance imaging, longitudinal view (tumor indicated by the arrow) total thyroidectomy with removal of surrounding lymph nodes, followed by radioactive iodine ablation and external beam radiotherapy to the neck. After 10 years, the patient underwent a resection of the apical segment of the right lung due to metastasis. Positron emission tomographycomputed tomography performed at the beginning of 2020 showed high concentrations of fluorodeoxyglucose in the left ventricular wall and right gluteal muscles. Magnetic resonance imaging (MRI) confirmed the presence of a tumor $(40 \times 36 \times 19 \mathrm{~mm})$ invading the left ventricle (FIGURE $1 A$ and 18 ). The woman remained oligosymptomatic. Upon excision via sternotomy, a $60 \mathrm{~g}$ mass spreading in the lateral and apical walls of the left ventricle, approximately $30 \mathrm{~mm}$ laterally to the anterior descending artery, was removed (FIGURE 1 C and 10). Hemostasis of the surrounding 

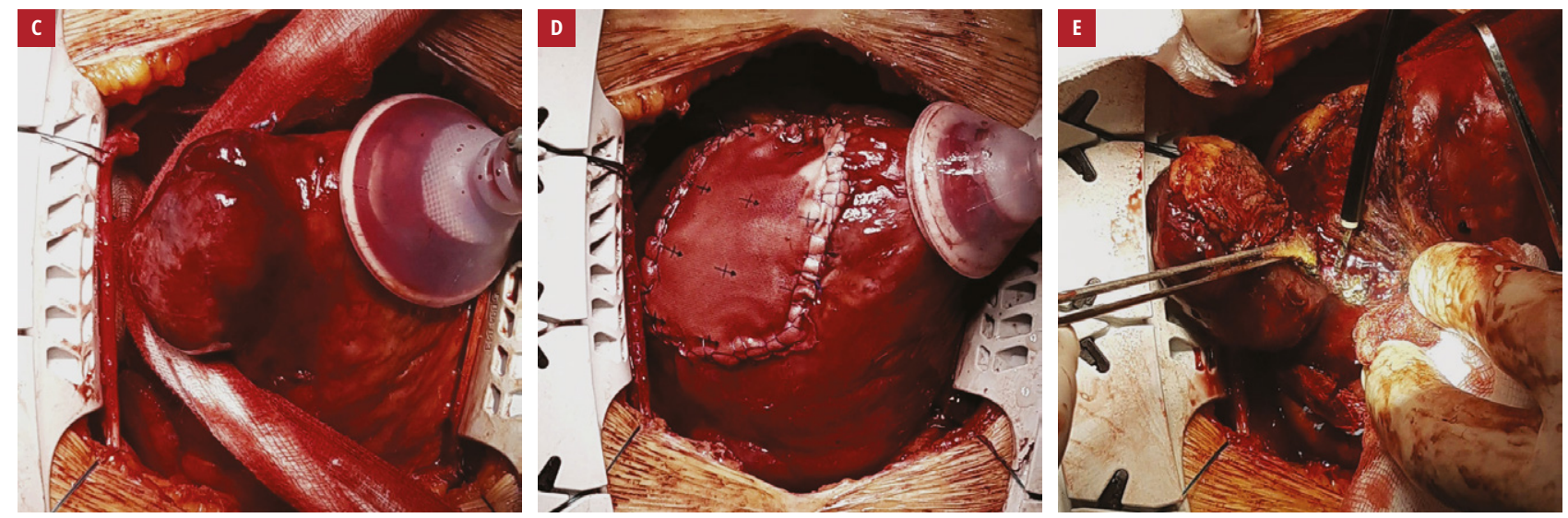

FIGURE 1 C - left ventricular tumor after sternotomy; D - removal of the tumor, periprocedural view; E - lack of tissue covered by a Dacron patch

tissues was ensured by argon plasma coagulation and the use of a Dacron patch (Figure 1E). Histological examination of the tumor revealed thyroid carcinoma. After recovery, the patient was transferred to the orthopedic department for further treatment.

The prognosis of cardiac metastases from malignant tumors is unclear. However, sudden death from cardiac complications or a need for a surgical intervention was observed in many patients. ${ }^{3}$ Cardiac MRI has become an established tool for detection and characterization of a suspected cardiac mass. ${ }^{4}$ Undoubtedly, transthoracic echocardiography remains the diagnostic modality of choice, but in the present case, MRI allowed full visualization of the tumor topography, thereby excluding pericardial involvement and infiltration of the ventricular chamber. Magnetic resonance imaging can be helpful in establishing an accurate diagnosis and monitoring of treatment, therefore, it should be performed in similar cases.

\section{ARTICLE INFORMATION}

CONFLICT OF INTEREST None declared.

OPEN ACCESS This is an Open Access article distributed under the terms of the Creative Commons Attribution-Non Commercial-No Derivatives 4.0 International License (CC BY-NC-ND 4.0), allowing third parties to download articles and share them with others, provided the original work is properly cited, not changed in any way, distributed under the same license, and used for noncommercial purposes only. For commercial use, please contact the journal office at kardiologiapolska@ptkardio.pl.

HOW TO CITE Zieliński J, Kołsut $P$, Kuśmierczyk M, Kuriata J. Left ventricular wall invaded by thyroid cancer metastasis. Kardiol Pol. 2021; 79: 89-90. doi:10.33963/KP.15721

\section{REFERENCES}

1 Kilfoy BA, Zheng T, Holford TR, et al. International patterns and trends in thyroid cancer incidence, 1973-2002. Cancer Causes Control. 2009; 20: 525-531.

2 Catford SR, Lee KT, Pace MD, et al. Cardiac metastasis from thyroid carcinoma. Thyroid. 2011; 21: 855-866.

3 Niemiec-Plich A, Maciejewski A, Woliński K, et al. Isolated cardiac metastases of pulmonary carcinoid detected 13 years after resection of the primary tumor. Pol Arch Intern Med. 2020; 130: 72-74.

4 Motwani M, Kidambi A, Herzog BA, et al. MR imaging of cardiac tumors and masses: a review of methods and clinical applications. Radiology. 2013; 268: 26-43. 